\title{
TRAVELLER'S TALES: \\ the stories migrants carry with them and their impact on a writer's life
}

\author{
Transforming Cultures eJ ournal, \\ Vol. 3 No 1, February 2008 \\ http:// epress.lib.uts.edu.au/journals/TfC
}

\author{
Manisha Amin ${ }^{1}$
}

\begin{abstract}
This paper represents one of a series that make up my non-traditional doctorate thesis. Like the others, it is a quest, through text, (both theoretical and fictional) as I write a novel and interrogate my role as a writer and a transnational of Indian descent. As such the paper takes on an autobiographical approach. It aims to explore notions of the story in migration, by overlaying direct travel routes with the stories that came on the plane and those that were left behind. As the child of migrants and as a fledgling novelist my own creative work has become the case study for my journey as I travel between longing and belonging, border lands, and the landscapes we live in externally and within the confines of our minds. My research, and my writing, was a search for a connection. An exploration into the transformation of personal and shared memory to written story and the impact of self and community in the process of creating a unique voice.
\end{abstract}

\section{Introduction}

"To begin to write - to attempt anything creative, for that matter, is to ask many other questions, not only of the craft itself, but of oneself, and of life.

The blank empty page is a representation of this helplessness. Who am I? It asks. How should I live? Who do I want to be?” (Kureishi, 2002)

Who am I and who do I want to be? As a writer I am informed by both my lived experience and an imaginary one, carried to me through the experience of migration.

\footnotetext{
${ }^{1}$ Manisha Amin is a PhD student at the University of Technology, Sydney.
} 
My experiences have been coloured by those of my transnational community and family.

Despite a developing literature on transnationalism there is little published work (other than fiction) on the shape, interaction and dynamics of transnational families and households (Chamberlain and Leydesdorff, 2004). In this essay I wish to look at the role of the family in the formation of identity through stories, by mapping transnational spaces and overlaying the stories that travelled with me as well as those I collected while growing up.

While some scholars have traced folktales (Blackburn 1996), others have focussed on the narrative of migration (Love, 1998). My work focuses on the stories that relate to my family’s migration experience.

By doing so I do not intend to speak for all writers or all migrants, or even all of my family. As Sollors reminds us in his introduction to Mary Antin's work "She may be speaking for thousands in one sense, but in another sense, her story does not even resemble that of her own sister.” (Sollors in Karakayali, 2005, p. xv).

Like Antin, my work is my own. A personal perspective, and narrative, informed but not limited to the memories of those that have come before me. One that adds yet another shade to the growing portrait of transnational families.

\section{Who owns the story?}

"To forget--this is the desire of all people, and when they encounter something unpleasant, they always say: If only I could forget! But to forget is an art that must be practiced in advance....

The more poetically one remembers, the more easily one forgets, for to remember poetically is actually only an expression of forgetting."

Nietzsche as cited in (Soderholm, 1993, p.56) 
"Where did we come from?” I'd ask. The answer was always - Tarapur, one of the villages on the Charotar plains of Gujarat. I knew that in the internal caste or gam classification Tarapur sat culturally between the six and the five villages, and that Tarapur boys and girls could marry into any of these villages. It was only later, some 20 years later that I learned that Tarapur has a different place in modern India as the home of a nuclear energy plant.

I knew that my grandparents and in one instance great-grandparent migrated to Kenya and travelled between Kenya and Gujarat. I knew they played an important part in the local Kenyan community - as principal of a school in Kisumu, a township, and as a politician and lawyer in Kenya. I knew that my great-grandfather was a cricketer on the Tanzanian cricket team.

I didn't realise that the Patidar community that I had affiliated with used to go by a different name. That of Kanbi.

At the turn of the twentieth century, Indian attitudes towards migration depended on caste status. For the upper castes migration was forbidden and was considered a polluting enterprise (Chandra, 1997).

In tracing the history of the Patidars, Pocock attributed the severe famines of 1899-1902 as the leading cause of migration to East Africa (Pocock, 1972, p.71). The "early migration abroad from the Charotar tract was [also] closely related to the job opportunities offered by British colonial rule in East Africa. During the first decades of the twentieth century especially, many Patidars from middleclass and lower middleclass peasant background migrated as passage or free migrants to countries like Kenya, Tanzania, and Uganda. Colonial rule and the completion of the East African railways offered these educated middle-class Patidars white-collar clerical occupations, and initiated a new era of economic opportunities to be exploited by the members of this peasant caste who took up a variety of commercial and professional activities” (Rutten, 2003, p.405).

My grandfathers were products of this time. Born in 1900 and before 1920 both were orphaned at an early age and raised by their grandparents, alongside brothers and sisters. 
While one studied in India and then moved to Kenya after marriage, the other followed in Gandhi’s footsteps ${ }^{2}$, studying law in England before travelling to East Africa.

The Patidars reinvested their wealth from East Africa back in Gujarat. This, together with an increase in tobacco cultivation (a cash crop), good monsoons and the rise in the price of agricultural produce during the second world war, increased the prosperity of the Patidars at home and in East Africa (Chandra, 1997). While this information was commonly discussed in my house, Chandra's assertion that the Patidars or Kanbis used this opportunity to legitimise the claim to a higher status was news.

"The remigration of many Patidars to India, their numerical strength and political presence as well as a change in caste rules helped to change their status. These rules included the banning of widow remarriage, bride price, meat eating and worship of the mother goddess to 'pure' Brahmanical customs like dowries, vegetarianism, and the worship of Lord Krishna (Hardiman, in Chandra, 1997, p.2).

The Kanbis brought themselves out of oppression and moved from a lower to higher caste status through migration and remigration and in doing so chose a new name for themselves. They became the Patidar community. In 1931, the Indian census recorded this change and provided a seal of approval (Chandra, 1997).

My father knew the story of the Kanbis. It wasn't however a story we were ever told. Not as a child or as an adult. It's not a story I heard in India, or in Great Britain, but rather one I found in the writings of scholars. I can tell you about the African freedom movement and our family's place in it. The buying and driving of the first car in Kisumu, and the role the family and others played in the development of communities and nation but not their own community.

The Patidar community is a strong and proud one yet none of the members of my generation, at least in my family (and I hypothesis in many others) would have been told or taught of the rise of this community and the way that travel formed a place in raising the community’s status. My cousins in England often refer to themselves as "Patels"

\footnotetext{
${ }^{2}$ My father's parents were heavily influenced by Gandhi and the Indian independence movement. My grandfather later become the president of the East African Indian Congress and was involved in Kenya's independence movement.
} 
rather than Indians. They joke about the fact there are more Patels than Smiths in Greater London and groan as my grandmother scours the Patidar directory for potential brides.

The story of how migration helped to transform the Patidars' status and their commonly known name isn't mentioned. These are thing that are not taught at western schools, or at the weekend Gujarati language group or on the UK and US Patidar community websites (Somani, 2007, Panchal, 2005). Somehow, during the motion of travel this one slipped through. ${ }^{3}$

I wonder if this is because to tell the tale is to acknowledge at some level that the community's caste and status was perceived as lower than it is today. Or maybe the story wasn’t personal or immediate enough.

I asked my father about the Kanbi/Patidar transformation. He tells me he knew all about it - using the internet. Later as I explore the concept of caste mobilisation and why this story isn't commonly told, he tells me it's not our story. The Patidars have always been a prominent group. When I mention the census dates of 1930 and the official recognition of the Patidar community, he disagrees, citing conversations with his father as the source of his knowledge.

I call my grandmother in England. I ask her about the difference between the Kanbis and Patidars. She says, "the Kanbis come from the Kathyavad side, we (Charotar Patels) come from the Kheda side of Gujarat. We were sometimes called Khedu (for the earth) Patels, they are the Kanbi Patels.” She tells me about a neighbour of hers in Kisumu in Kenya. "He was a very good man. The Kheda Patels used to have more education but now they are all the same. The Kanbis are very fair (in colour). We say that we are all descendants of Lav and Kush (Lord Rama’s sons), but the Kanbi Patels descend from Kush who was very fair, and the Kheda Patels descend from Lav who was dark.”

My grandmother would have been born around the time of the 1930 census. She lived in both India, Kenya, Tanzania and Zanzibar. She is the only one of my grandparents alive

\footnotetext{
${ }^{3}$ I did however find more information on an Indian site website, published out of Mathya Pradesh. Patidar, S. (2004-05), Vol. 2007 Patidar Samaj, Mandsour, Madya Pradesh.
} 
at present. I asked her if the Charotar Patels were always called "Patidar" and she concurs, at least from her recollection.

So the questions I ask change. Clearly I'd lost something in the translation between journals and oral history. Is this a story that has been left behind, or a story that doesn't relate to 'my' Patel community. And as a generation passes away, how do we know the "truth" and is there only one "true" version? It's also interesting to me that both my father and I found the story of the Kanbis on the internet. The medium produced the facts, but certainly not the personal/subjective context that my Grandmother's version provided.

\section{A model of migration}

Transnationalism and more recently transmigration are relatively new terms that have gained currency among scholars of migration and migrant adaptation. Szanton Blanc, Basch, and Glick Schiller, pioneers in this area of study, whose work focuses on transmigration as one key transnational process "define "transmigrants" as migrants whose lived experiences transcend the boundaries of nation-states" and "who develop and maintain multiple relationships-familial, economic, social, organisational, religious, and political-that span [these] borders” (Basch, et al, in Blanc et al., 1995, p.22).

Voigt-Graf, who has in the past written about on the geography of migrant transnationalism uses an interesting model to map the migration flows, to developing a typology of transnational spaces (Voigt-Graf, 2004). Her research focuses on the transnational spaces of three communities, the Punjabis, Kannadigas and Indo-Fijians. I have used her model and terminology as a basis to map and discuss the typographical space of three generations of my own family.

As Voigt-Graf notes, "some 20 million people of Indian origin today live in all corners of the globe. The fact that many descendants of the nineteenth-century migrants have undertaken a second or third migration, not back to India but usually to industrialised countries, makes the Indian diaspora a very multifaceted one. ...Many overseas Indians are linked not only bilaterally to India but also to several nodes of the Indian Diaspora. The migration of family members to different countries, as well as the considerable 
number of Indian twice migrants, have contributed to these complex patterns” (VoigtGraf, 2004, p.26).

My family fits this pattern, having moved from Gujarat three to four generations ago. I have chosen to follow the migration flows and stories of three generations, starting with my grandparents (maternal and paternal) and that of the extended family.

The terminology used by Voigt-Graf that I intend to use can be seen in the following table.

\section{The spatial components of a geography of transnationalism}

Cultural hearth: The country, region or place of origin of migrants and their descendants which often forms an important node in transnational networks. Since this term is understood in a geographical sense referring to the place where the culture of migrants originally developed, it does not imply an essentialist understanding of culture.

New centre: If personal links to the cultural hearth are lost, the country where migrants and their descendants have lived sufficiently long to regard it as their home can become the new centre of a transnational community.

Diasporic node: A country, region or place where migrants have settled long enough and in sufficiently large numbers to have created a permanent presence as a community, even if individual migrants are merely passing through.

Node: Countries, regions or places that are linked by flows. The cultural hearth (or new centre) and the diasporic nodes together make up the nodes of migrant transnational networks.

Flows: Flows between nodes may include migration flows and flows of people, products, money, ideas, cultural goods, and information. They can be one-way or two-way.

Offshore flows: Flows between two diasporic nodes.

Transnational space: The transnational space is the sum of the nodes and flows between them. The emphasis is on the fact that it is shaped by social activities and in turn shapes them. The transnational space as a whole comprises different sub-spaces defined by the sphere of transnational activities such as transnational economic spaces and transnational cultural spaces.

(Voigt-Graf, 2004, p.24) 
Voigt-Graf suggests that the complexity of transnational spaces will evolve and become more complex over time (Voigt-Graf, 2004). This is certainly the case in my family, with migration flows increasing with each successive generation.

Table 1. Mapping three generations of migration

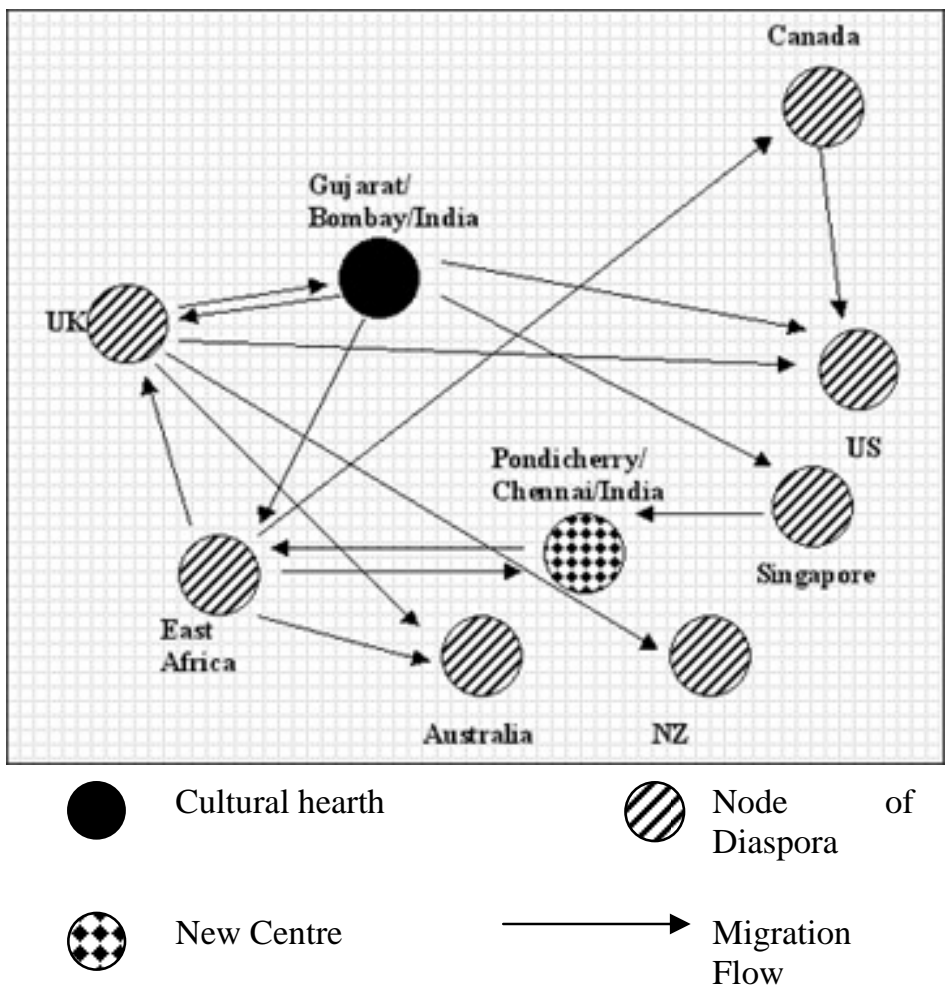

Transnational space

The diagram provides a general picture of the family's migration.

- The first generation migrated to East Africa, remigrating to India (both Gujarat and Pondicherry) and The United Kingdom (UK).

- The second generation migrated from India and/or East Africa to the UK, Australia, Singapore, Canada, the America and/or remigrating to India

- The third generation remained in one of the countries of migration or themselves migrating to New Zealand, Australia, India, and the US.

Interaction through this transnational space has also changed as the older generation becomes less mobile, so that the transnational flow revolves around the nodes that "house" the elders of the family. As a result, through my childhood, our extended family travelled to meet each other in either Pondicherry, where my parental grandparents retired, or to Britain, where my maternal grandparent migrated. In recent 
years, as other members of the family return to Gujarat, this too has become a key centre.

By overlaying stories on the model of the transnational, space the flows take on a different topography. With some stories coming directly from my cultural hearth, while others flowed with the family - often to be told at the cultural hearth, new cultural hearth or the UK, a diaporic node "housing” the greatest number of family members.

\section{Coming to Australia}

"No story is ever told just once. Whether a memory or funny hideous scandal, we will return to it an hour later and retell the story with additions and this time a few judgments thrown in. In this way history is organized” (Ondaatje, 1982)

Migration provides rich material for the writer. As George Lamming, the Barbadian novelist notes, generations of writers have found inspiration and meaning, pleasure and pain in the condition of exile (Lamming, 1991). However not all migrant novels are about migration. Nor is the act of migration itself necessarily the critical issue in those that are. "What links these novels is not simply the themes of migration, the journey, the settlement, the yearning for home, but also the use of memories in their construction. Migrants perhaps more than many people are made by their memories of their birthplace, their homeland, those left behind - interruptions in their life narratives that require resequencing, remodelling and reinterpreting as newcomers incorporate and surpass the past” (Chamberlain and Leydesdorff, 2004, p.1).

This thread between memory and migration coils in different ways, depending on the context of migration. Those who write as a result of trauma and separation have a different story to tell than those who write from the perspective of belonging, while the position of being separate from people around them can also create a different perspective. The fabric of stories, the material one uses is also coloured by the notion of home. A country of birth may not necessarily be one's cultural hearth and the memories one leans towards may not be one's own. The twice migrants that Rutten speaks of (2003) and their children have their own different story to tell, just as I do: 
I'm 12 years old. I crawl through the space under the house, built on brick stilts, and the sand. The air is musty. In the darkness I look out, without much success, for red-back spiders as I journey into the past. There, on the right, where the space between the soil and the house is low enough that I need to crawl, I find two metal cases. These are the trunks that my parents had shipped to Australia when we migrated from Kenya. I drag one as far out as I can. Enough to open it. The heavy metal latches move easily. As if they'd only been opened the day before. Inside I find music records. Heavy, flat and black.

My parents had forgotten them, these 45's. They couldn't play them on the stereo, but had to get them re-recorded onto tapes. It took a few months before we could listen properly to those songs. Slightly scratchy but warm, they fill the house with music that echoes from room to room. Music I didn't much understand, but that brought back memories for my parents

Later we drag the trunks out. One is baby blue the other a light, faded green. My sister and I pick one each, and paint them beige and chocolate brown. I still have my trunk. It sits in my child's room, and houses my memories. Photo albums and loose images captured from my grandfather's political days in East Africa to my three year old's birthday party in Sydney.

And When a Brimful of Asha (on the 45) is released by British-based band Cornershop, I buy it, and remember the records I found deep under our house.

Like the immigrants to New York City in the late sixties, most of whom entered the country under occupational preferences, as individuals, or nuclear families (Gupta, 1997), our family, when moving to Australia in the early 1970s had no social networks in the country. The family moved because of the political unrest in Kenya, and my mother's need for a warm country. My father was offered a job before he left Kenya and we migrated as a family unit.

I was five at the time and Kenya became the country I was born in, a diasporic node rather than cultural hearth. My metal trunk carries pictures from safari, photos of me 
playing in the mud with my once yellow rabbit. I brought with me a language that diminished in importance until it too was exiled. Only a few words remained. I couldn't remember how much of my memory was my own and how much was a memory of stories told to me by my parents as we grew up.

Chamberlain notes that the "multi-layering of memory, language and narratives are indicators of ways in which culture shows recall and recounting. Families themselves become sites of belonging, part of the imaginary unity though which a transnational family may seek its identity” (Chamberlain and Leydesdorff, 2004, p.1).

As a child my mother told me stories. Not so much of Kenya, but rather mythological stories from India. She'd tell me about the Pandava brothers or Krishna. When the curtains closed, blocking out the sun, still bright at 7.00pm in the Sydney summer, we would travel, not to Kisumu but to a long lost India. A landscape made up of palaces made of wax, serpents and mountains that could be lifted on a little finger.

And there was always music - Australian and Indian. I grew up singing Alex Hood and Indian nationalist songs, dancing to Chitti Babu and studying to Omkarnath Thakur. The decision to listen to one or the other was never a conscious decision about culture so much as choosing the music that would feed a particular mood.

We learnt about our new country in class and in the playground. Once a month, my grandfather would send us comic books from India our cultural hearth, and the new cultural centre of my paternal family. The Amar Chitra Katha comics were started in India by Anant Pai, as a way of using the popular medium of comics to teach Indian children about their cultural heritage. The idea came while watching a quiz programme on television; where he saw that the children from English-medium schools knew about Tarzan and the exploits of Greek gods but could not answer simple questions about the Ramayana (AmarChitraKatha, 2005).

"The world of books and literature can provide the breeding ground for the secret life of immigrant children” (Karakayali, 2005). This was certainly true in my case. There was another world that I could travel within the pages of a book. The Amar Chitra Katha comics became part of this world. They provided me with a direct connection to India. I 
knew that they were read by children there as well. The pages smelled of a different place and the advertisements for Amul Butter, Twinkle cakes, and Poppins sweets added to the experience.

Three books would arrive every month to be read and then shared amongst our Indian friends. However, these stories didn't always portray the "truth” either. The India of Amar Chitra Katha was populated by kings, queens, gods and goddesses. It provided a sanitised and entertaining view of a nation, with its best foot forward. Later, the arrival of Peter Brook’s Mahabarata cast a darker but just as acceptable shadow.

Sometimes my father would talk about Kenya. But this was more often than not in the context of the family. Stories about "Why I started to eat meat" or "How your grandfather carried Gandhi's ashes”. These stories were personal stories about our family. They were for the most part positive. The negative stories were also personal and more often than not linked to racism. My mother's experiences in Britain in the 60s as a student and later in the 70s as a young mother and later my parent's experiences when they returned to India with two young children. Not only had the India of their childhood changed, so had their expectations of how they should be treated. They recount a story of the booking they made at the Taj Group Hotel in Bombay, and how because they were Indian and not white, they were treated differently to the other passengers and were forced to find another hotel in the middle of the night. This difference wasn't a comparison between them and the 'native' Indian as much as the difference between their treatment and that of the other (non-Indian) travellers. During the 1970s and 1980s I often heard stories at dinner parties, where friends would relate their disgust that Air India as an airline was far more deferential to non-Indians than they needed to be. We would always travel by Singapore Airlines or AirItalia.

These stories, of the small everyday encounters of the generations before me joined together in my consciousness to form a picture of my family's transnational space and its personal relationship with India and other related diaporica nodes. A relationship that as each generation migrated or returned, was different, but just as ambiguous to my own. 
The fluidity of a border relates to the fluidity of migration. Connection, disconnection and re-connection. Nothing is black and white but rather a nostalgic rose that, like the plant itself, can draw blood unexpectedly.

There is no opposing side in this story. It's not a tale of intergenerational conflict, although this has occurred. Nor is it a tale of migrant versus second generationer - the lines are too blurred. As Karakayli notes: "not only do... [stories of self] shatter the image of the "immigrant family" as an undifferentiated entity, but they also reveal that there is no uniform, "typical" relationship between the immigrant child and his/her family” (Karakayali, 2005).

When I speak of family, I normally refer to my extended family. We would travel from different countries to meet in India in Pondicherry or in London. The children converged to form a single unit. We saw ourselves as outsiders - different from the local Indian children, including our cousins - but as a unit ourselves, regardless of our diosparic node. Later, as I grew older, these meetings provided another source for stories. Stories told almost by mistake, as an aside. Stories that changed meaning and shape of my own personal landscape.

“...of course they didn't get on, her mother-in-law tried to poison her" or "we don't talk to him, he burnt his wife. The police hushed it up of course” or “ they poisoned my dog with bad meat" or "your grandmother would walk the perimeter of the fence at night with a pango (machete)"

These half heard tales had a double lure. The hidden story, and the lure of the exotic. These family stories were not only from the cultural hearth. Each one provided a change to my inner, imaginary landscape. Answers I created were always far more interesting than the real ones. They were in fact another place where I could travel. A world of my own making.

"The voice of a minority writer can not only subvert dominant stereotypes in the community, but can also put the writer at a distance from his/her community... [nor are they] simply a spokesperson for the minority, whose members might be indifferent to literature” (Karakayali, 2005). All writers, through the act of writing are outsiders to 
some extent. It is my view that the perspective brought by being a child of many worlds makes this easier. One is used to travelling through discordant stories. Some that are accepted as fact, others that aren't. The truth is only an issue in terms of its relative value.

My story map follows:

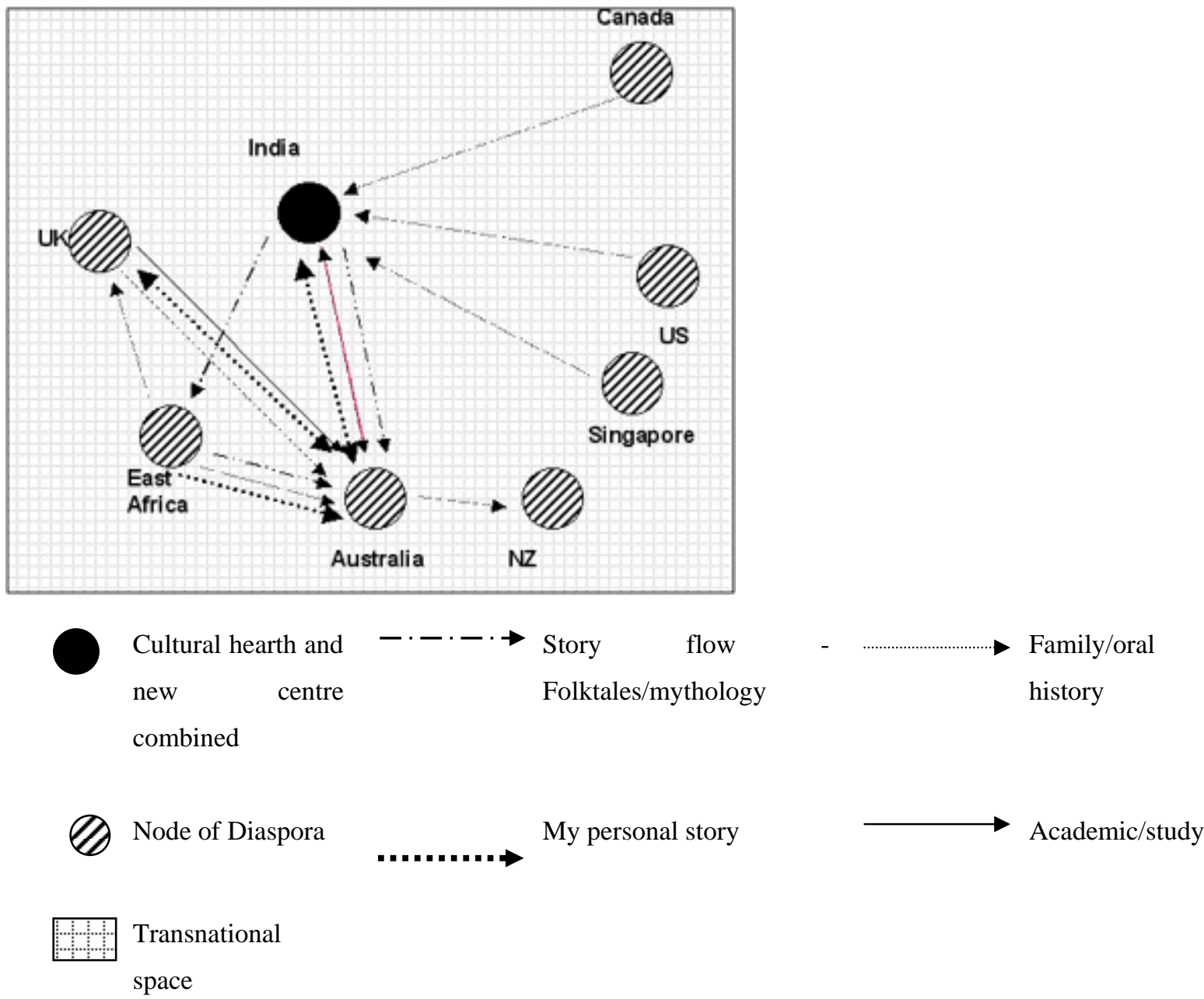

This diagram uses the concepts of Voigt's physical mapping, and overlays the flow of story from cultural hearth, to diasporic nodes. Rather than mapping each generation, I simply trace the stories I have been told from country of origin, or node of the story originator (the person quoted in the family as the source). All stories therefore link to Australia, my place of residence.

This map places a real emphasis on the cultural hearth, the node with the oldest transnational member (my grandmother) and the area that the majority of the second generation (my parents) migrated from, that is East Africa. While stories flow between 
other areas I would hypothesise that a similar map drawn from the perspective of my cousins in Britain or Canada would look rather similar, with the their country of residence replacing Australia.

The internet has brought with it the ability to search for one's self online. The telephone is another means. I can call my grandmother in England or my Aunt in India to obtain their recollections of an event without travelling from country to country. Email and discussion groups form their own communities. This direct form of communication that doesn't involve migration has also changed the map but it brings with it different issues. These are stories and ideas that one actively searches for rather than the ones that are actively told.

\section{The same - but different}

When travelling, I say I'm from Australia

When in Australia, I call myself Indian, or East African Indian

In London I call myself Australian - unless the person is of Indian decent, then I'm a Tarapur Patel

When in India, I say I'm from Australia and that I'm Gujarati...

So what does that make me and what is Indian anyway?

A new study by researcher Julie Furnell has, for the first time, compared the behaviour and physiology of a southern hemisphere migratory and non-migratory subspecies known as the Silvereye (Morgan, 2007).

The researcher looked at differences in activity, moult, body weight, fat levels, diet and orientation patterns of the Tasmanian Silvereye to its non-migratory counterpart, the Mainland Silvereye. (Morgan, 2007). It was found that the Tasmanian Silvereyes moulted earlier and faster than the mainland birds and carried more fat than the mainland birds as they needed it for migration. Their migratory nature had made them the same, but different. 
In the winter of 1989-90, Gupta interviewed Indian immigrants living in New York. When she asked four second-generation women the question, "what is Indian about you?” What emerged was a contested terrain where “Indian” had no fixed meaning (Gupta, 1997).

Both the migrant group and the family remaining behind have different perceptions of the other.

I remember as a teenager, thinking that in India one didn't have to do specific things, such as be vegetarian or have an arranged marriage to be classed as a "real” Indian. You were Indian by the fact of your birth and your family. Migrants had a different perspective with an emphasis on conforming to a traditional culture.

As one of Gupta's interviewees puts it:

"My father's nephews and nieces in India do things he would still say no to. They wear their hair short, go out with friends, hold hands [with the opposite sex].” Another "wondered about her father's "narrow outlook," which she felt was an anomaly, considering his westernization and the increasing "liberalization" of the Indian middle-class ethos that she noticed during her trips to India. For the first generation, however, this liberalization adds to their sense of authenticity. Developments in India serve as a measure of their success in bringing up their children traditionally. As preservers of culture, they take pride in being more Indian than Indians in India” (Gupta, 1997, p.581).

This difference can also be seen through the views of villager, speaking about their Patel relatives when interviewed by Rutten and Patel.

“Many of them were never very religious when they were staying in Africa or when they came to Britain. But now that they are retired, they suddenly have a need for Indian culture and rediscovered religion. However, many of them have already become too westernised. They are not even able to sit 
crosslegged on the floor for a long time and their stomachs can no longer stand our drinking water” (Rutten, 2003, p.412).

When I travelled to India in my twenties, my cousins in Gujarat, who had never left India, thought my interest in Indian classical music was old fashioned and constantly tried to refill my bottled water with tap water. The water in this instance symbolising a contested space. Are you one of us, or not?

Like the Silvereye, migration had changed us. Those of our family that moved and those that stayed put. The difference is not just in terms of the way I walk and talk, but on the simplest of levels, I cannot drink the water in the villages or cities without a filter. Without getting sick. The reality of India is different from the edited version told back home in Australia.

Still there is a connection, a need to belong and an acknowledgement of difference and distance felt whenever I open that metal trunk made of memories.

\section{Crossing the borderlands.}

The 'beyond' is neither a new horizon, nor a leaving behind of the past.... Beginnings and endings may be the sustaining myths of the middle years; but in the fin de siècle, we find ourselves in the moment of transit where space and time cross to produce complex figures of difference and identity, past and present, inside and outside, inclusion and exclusion. (Bhabha, 1994, p.1-2)

Then I look at my maps of migration and story, the spaces between each node, the flight path of each journey seems just as interesting as the nodes themselves.

Gloria Anzakdua uses the metaphor of border crossings, or border consciousness as a place of contradictions that creates articulations of in-betweeness. It provides a path for understanding the realities of borders, both physical and cultural, that manifest in the stories that are told and the spaces within them (Anzaldua, 1987). 
These are places where country and culture collide and the symmetry of ones narrative is jarred by the subcontext translated by a different generation.

Those of us who choose to write do so because there is a need to tell a story. When I first started to write creatively I was told to write about what I knew. To my consternation all my stories began and finished in India. Not the real India, rather a place of my collective imagination. With the memoir genre, work is seen as "not invention and novelty but real life and old events re-narrated, the past under threat of extinction re-membered. Thus, writing a memoir implies re-living a past” (Lim, 2003, p.442). While my work was fiction, in someway it too was the re-narration of a place and ideas that I had grown up with - that had travelled with me across continents, until they became invisible threads, that bound my bones and supported me on my journey through an imaginary terrain, called "India” but not.

I find the notion of in-betweeness, with all its ambiguity an easier one to navigate than one of two worlds with opposing views. "A border is in a constant state of flux. A vague and undetermined place created by the reside of an unnatural boundary” (Anzaldua, 1987).

While there are many issues that a second and third generationer has to deal with, migrants such as myself have one real advantage. By spanning more than one world, we can view the world through different eyes, each true and legitimate in its own way.

As a colleague noted when talking about his second-generation Persian daughter - a budding visual artist “ she can take parts of her Persian heritage and exploit it - because it's exotic” (Roshan, 2006). Perhaps this knowledge, an ability to walk between multiple worlds gives creative artists from second and third generations another perspective, a patchwork quilt comprised of pieces that somehow when sewn together make a new and unique whole. One that is not as clean or clear as the whole, but one that with each prism of glass creates a different rainbow. One that isn't easy to hold or to quantify, but one that informs the creator's journey. The path they take in their work the colours they choose and the words they decide to discard. Because ultimately, writing or creating, unless the story is about the migration, these issues are never at the 
fore because the story, the one that's been dancing at the edges of your mind, that is the most important thing.

\section{Bibliography}

Amar Chitra Katha (2005), Vol. 2007 CBO. Available online at: <http://www.ackmedia.com/index.php>

Anzaldua, G. (1987) Borderlands frontera: The new mestizu, Anut. Lute, San Francisco.

Bhabha, H. K. (1994) The Location of Culture, Routledge.

Blackburn, S. (1996) "The Brahmin and the Mongoose: The Narrative Context of a Well-Travelled Tale”, Bulletin of the School of Oriental and African Studies, University of London, 59, 494-507.

Blanc, C. S., Basch, L. and Schiller, N. G. (1994) “Transnationalism, Nation-States, and Culture”, Current Anthropology, 36, 683-686.

Chamberlain, M. and Leydesdorff, S. (2004) “Transnational Families: Memories and Narratives”, Global Networks, 4, 227-241.

Chandra, V. P. (1997) "Remigration: return of the prodigals - an analysis of the impact of the cycles of migration and remigration on caste mobility", International Migration Review, Vol. 31, 162 - 170.

Gupta, M. D. (1997) "What is Indian about you? A gendered transnational approach to ethnicity”, Gender and Society, 11, 572-596.

Hardiman, D. (1981) Peasant nationalists of Gujarat: Kheda District, 1917-1934, Oxford University Press.

Karakayali, N. (2005) "Duality and Diversity in the lives of Immigrant Children: Rethinking the 'Problem of the Second Generation' In light of immigrant autobiographies”, Canadian Review of Sociology and Anthropology, 42.

Kureishi, H. (2002) Dreaming and Scheming, Faber and Faber Limited, London.

Lamming, G. (1991) The pleasures of exile, University of Michigan Press.

Lim, S. G.-L. (2003) “Embodied Memory and Memoir”, Biography, 26, 442-444.

Love, P. (1998) “The Narrative of Migration: Nahal's Azadi in Comparative Context”, Alif: Journal of Comparative Poetics, 65-74.

Morgan, F. (2007) “True migrants: Tasmanian silvereyes”, In U: magazine. Available online: <www.u.uts.edu.au>

Ondaatje, M. (1982) Running in the Family, McClelland \&Stewart, Toronto.

Panchal, P. (2005) Federation of Patidar Associations, 2007 Federation of Patidar Associations, Wembley London. Available online: $<$ www.patidars.org/home.asp>

Patidar, S. (2004-05) Vol. 2007 Patidar Samaj, Mandsour, Madya Pradesh. Available online: <www.patidarsamaj.org/introduction.htm>

Pocock, D. F. (1972) Kanbi and Patidar, Oxford University Press, Oxford. 
Roshan, S. (2006) (Ed, Amin, M.) Sydney, pp. Verbal discusson.

Rutten, M. P., Pravin J. (2003) “Indian migrants in Britain”, Asia Europe Journal, 1, 403 - 418.

Soderholm, J. (1993) "Byron, Nietzsche, and the mystery of forgetting (Lord George Gordon Byron, Friedrich Wilhelm Nietzsche)”, CLIO, 23, 51 - 63

Sollors, W. (1997) In the Promised Land M.Antin, Penguin, New York, pp. i-xxi.

Somani, V. (2007) Vol. 2007 R. O. Somani Charitable Trust, Bombay, pp. General listing of Gujarati Samaj orgs / Marathi Mandals in USA, including the Patidar community sites. <www.karmayog.com/lists/gujmarorgusa.htm>

Voigt-Graf, C. (2004) "Towards a geography of transnational spaces: Indian transnational communities in Australia”, Global Networks: A Journal of Transnational Affairs, 4, 25-49. 